\title{
Scenario building: Uses and abuses
}

\author{
Philippe Durance* ${ }^{*}$, Michel Godet \\ Conservatoire national des Arts et Métiers (CNAM) Paris, LIPSOR, 2 rue Conté - 75003, Paris, France
}

\section{A R T I C L E I N F O}

\section{Article history:}

Received 18 March 2010

Received in revised form 8 May 2010

Accepted 15 June 2010

\section{Keywords:}

Scenarios

Strategy

Prospective

Foresight

Workshops

\begin{abstract}
A B S T R A C T
Scenarios hold little interest if they are not pertinent, coherent, and plausible. Although foresight requires a rigorous approach to address complex problems, the tools must also be simple enough to be easily used. Since the mid-1980s, the approach in strategic prospective workshops (a term that reminds us of the participatory nature of the French approach) has proven its effectiveness in meeting these criteria (simple, rigorous and appropriable; i.e., may be appropriated by participants). The authors try to reply to simple and important questions: What is a scenario? How to judge the quality of a scenario? Which strategies for which scenarios? These questions remind us that applications of strategic foresight tools are contingent and modular. They could also involve the stakeholders from upstream to downstream, as seen in the agro-food sector. Finally, they argue that the future still has to be built and that futurists produced too many scenarios and not enough projects.
\end{abstract}

(c) 2010 Elsevier Inc. All rights reserved.

\section{What is a scenario? ${ }^{1}$}

A scenario is not a future reality but rather a means to represent it with the aim of clarifying present action in light of possible and desirable futures. Foresight must master the constraints of the present. In order for scenarios to be both credible and useful, we think that they have to respect the following five conditions; pertinence, coherency, likelihood, importance, and transparency. Transparency is another indispensable condition for both the credibility and usefulness of scenarios. The same goes for defining problems, the choice of methods used, and the results and conclusions of the scenarios. Too often, unfortunately, scenarios are meticulously written but then the reader has difficulty drawing the pertinence and coherence of their content; or the scenario is so poorly written that the reader quickly loses interest. Thus, without a careful and attentive reader, many scenarios pass as credibleas if the reader is guilty of not having understood the underlying meaning. Without this transparency, participants will not be vested in the results of the scenario planning process, and the intended audience will not believe the scenarios. Of course, transparency and attractively written scenarios do not guarantee quality.

There is no single approach to scenario planning, but rather three principal approaches - 1) that introduced by Herman Kahn ${ }^{2}$ in the United States in the 1960s at the Rand Corporation, 2) that developed by Hasan Ozbekhan and 3) DATAR (a French governmental regional foresight department) from the late 1960s and early 1970s [1] $]^{3}$. Kahn had been the first to build and use

\footnotetext{
* Corresponding author. Tel.: + 33632336270 .

E-mail address: philippe.durance@cnam.fr (P. Durance).

1 Since the early 1980s, the term scenario has been codified within academic study of management, notably by the management guru Michael Porter (1999) [3].

2 Herman Kahn (1922-1983), was a physicist and mathematician, and worked at the RAND Corporation in the late 1940s, 1950s and early 1960s. At the RAND, he co-directed the United States Air Force projects which inspired his first book entitled, On Thermonuclear War (1960), in which he analyzed the possible effects of a global nuclear war. In 1961, Herman Kahn founded the Hudson Institute, a think-tank which provides independent counsel on multiple issues. Kahn is considered one of the founders of futures studies, and contributed both to the discipline's theory and methodology (scenarios, using mathematical models for forecasting, etc.). The scenario method was described in two books; The year 2000: A framework for speculation on the next thirty-three years (1967) and Things to come; thinking about the seventies and eighties (1972). The Hudson Institute also worked closely with the French ministry, Datar, in 1970 and 1971.

${ }^{3}$ For more information on the history of the French school and its relationship to American methods, see Philippe Durance's article "Reciprocal Influences in Future Thinking between Europe and the USA" in this issue.
} 
scenarios at the Rand Corporation and then at the Hudson Institute. For Kahn and Wiener [2], a scenario is a "[set of] hypothetical events set in the future constructed to clarify a possible chain of causal events as well as their decision points."

More simply put, a scenario is a description (usually of a possible future) which assumes the intervention of several key events or conditions which will have taken place between the time of the original situation and the time in which the scenario is set. The word scenario is often used in an abusive manner to qualify any particular set of hypotheses. However, these hypotheses must satisfy five simultaneous conditions in order to be considered a scenario. These conditions are pertinence, coherence, likelihood, importance, and transparency. Furthermore, a distinction must be made between the two major kinds of scenarios; exploratory and normative. Exploratory scenarios are concerned with past and present trends and lead to likely futures. Normative scenarios are constructed from alternative images of the future which may be both desirable and feared, and are conceived in a retroprojective way. Thus, exploratory scenarios are devoid of human values, whereas normative scenarios are the expression of human values. Both exploratory and normative scenarios can be either highly similar or highly contrasted to one another, depending upon whether they take into consideration the most probable or the most extreme trends respectively.

Today, two scenario methods are used most frequently: the one which we had developed at the Society of Applied Economics and Mathematics (SEMA) in 1974 and then subsequently at the CNAM (Conservatoire national des Arts et Métiers), and those developed at SRI (Stanford Research Institute). The two approaches are very similar and their various stages and functions differ only slightly. The spectacular growth of the French school of foresight, which began in the 1950s, continues apace by developing methods which are both rigorous and participative. The rationality of these methods allows users to deal with the complexity of their business environment, while stimulating imagination and reducing the incoherences that often appear in group processes.

\section{The devil is (often) in the details}

Scenarios are not a requisite part of strategic foresight. Foresight and scenarios are not synonymous. Too many foresight studies get bogged down because the group has decided to write scenarios. However, a scenario is not an end in itself. It only has meaning as an aid to decision-making in so far as it clarifies the consequences of current decisions.

Scenario planning requires time to be done right, and a 12- to 18-month timeframe is not rare. Time is needed in prospective and strategic diagnoses so that scenarios involving the environment may be developed and that the main stakes for a specific organization based on possible futures, as revealed by scenarios, may be reviewed. Finally the various action plans have to be drafted. On a practical note, busy executives are very involved in this process and each stage needs to be confirmed by a management team or committee.

Time is required, among other things to assemble such an operational team. Consider the OECD Interfuturs team [4] whose leaders declared that during the three-year study, there was little time to properly consider the scenarios they had developed. In addition to the time it takes to undertake the Foresight study, you should plan on extending the schedule an extra year to accommodate the distribution and integration of the results. In most corporate and administrative organizations, such teams will be required to report within the year. In extreme cases, policy-makers may launch a Foresight study that they wish to see finished in a matter of weeks. In this event, the prevailing conditions are rarely ideal, thought it is better to light a candle than curse the darkness. Good judgment dictates which questions should be addressed, given the limited timeframe and the means available. The question then becomes: How can the work be done in such as way as to remain both credible and useful to the decision-makers?

Given a short time-frame, it is often advisable to limit the scenarios to several key hypotheses, say four to six. Beyond such numbers, the sheer magnitude of possible combinations is overwhelming. On the other hand, limiting the number of scenarios to four by combining two hypotheses, as advocated by the Global Business Network (GBN) and Sanford Research Institute (SRI) methods, seems far too reductive. Scenarios constructed around five or six fundamental hypotheses, set the background for further strategic thinking focused on simple 'what if' or 'what for' questions.

This shortcut requires the team to do a quick, but in-depth preliminary study on the key variables, trends and stakeholders involved. One final difficulty that arises when building scenarios and selecting methods relates to lead-times. Even if one had months or a few years to finish the assignment, there is an inherent risk in the start-up phase because team members or even the team leader may change as the study progresses. A futures study rarely survives after the departure of its initiator. In large organizations - given the mobility of personnel - it is preferable to limit the length of the project to one year and to plan for interim status reports.

\section{Which strategies for which scenarios?}

There are no statistics on the future! When faced with an uncertain future, personal judgment is often the most reliable element available. As a result, it is important to gather as many informed judgments as possible and then forge a consensus. However, as with a good gambler in a casino, one single bet does not count for much; rather, it is the net winnings that make the difference overall. Also, just consulting outside expertise is often the subject of controversy. Our conviction is simple in this regard; insofar as an expert represents a fresh perspective, his or her point of view should be taken into consideration. In the end, the participants will make up their own minds as to the reliability of expert advice and orient their action accordingly.

The uncertainty of the future can be evaluated across a number of scenarios which share the field of probable futures. In principle, the more scenarios elaborated, the greater the uncertainty. However, it is important to take into consideration the content of the various scenarios since the more probable among them may be either very similar or quite contrasted to one another. In theory, two possible situations may present themselves. If certainty is strong, which is to say, a limited number of 
rather similar scenarios occupy a majority of the field of probable futures, then one could then either opt for a risky strategy (taking a gamble on one particular scenario among the more probable), or for a robust strategy which will likely withstand any possible foreseeable scenario. If the certainty is weak (the majority of possible scenarios cover a wide field of probable futures, or the more probable scenarios are highly contrasted), then one ought to adopt a flexible strategy which includes the maximum number of reversible choices. Of course, the risk with this approach is risk aversion. Adopting a relatively conservative strategy will not likely lead to great losses; but neither will it lead to great gains. In the end, such a strategy may ultimately represent a lost opportunity. Also, experience shows that, in general, a small number of scenarios are enough to cover most probable futures.

\section{Tools for methodological rigor}

Since the beginning of time, humankind has considered the future. As long as foresight remained a solitary exercise, it had no need for rigorous tools. As anticipation began to be used in the service of collective action, the need for rigorous tools arose naturally. To respond to these needs, foresight first exhausted the tools of operations research, then systems analysis, then strategy, and then it finally developed its own set of tools. Although Foresight may be considered by some a soft science, there is a need for rigorous methods to orient action towards a desired future. The toolbox of strategic foresight allows one to apply rigor to the foresight process by posing the right questions and reducing incoherences which often accompany group processes.

Several tools have come to the aid of strategic foresight. They include structural analysis for identifying the key questions concerning the future; stakeholder analysis to identify the influence of various stakeholders, establish the relationships amongst them, as well as the stakes involved; morphological analysis to consider the entire field of possibilities and construct scenarios; expert analysis (such as Delphi or Reigner's abacus) to assign probabilities and reduce uncertainty; and multi-criteria analysis to identify and evaluate strategic options. Morphological analysis, rediscovered in the late 1980s, has become among the most popular tools. Curiously, it had long been used in technological forecasting, but seldom for economic or market foresight ${ }^{4}$. Nevertheless, it lends itself perfectly to the construction of scenarios. Using morphological analysis, a global system can be decomposed into dimensions (key questions concerning the future). These dimensions are; demographic, economic, technological, and social/organizational. Each of these dimensions has a certain number of likely hypotheses (see below).

If foresight requires rigor to broach the complexity of contemporary problems, its tools need to be sufficiently simple so as to remain accessible to those who will use them. Since the mid-80s, we have developed strategic prospective workshops which were set up to respond to these concerns, notably at Renault. These workshops serve to introduce the methods of strategic foresight to the participants, and also gather important preliminary data. They also get teams used to working together. Ideally, they involve several dozen people ${ }^{5}$ and provide an immersive introduction to the exciting work ahead. The workshop objectives are to pose the best possible questions and to rid the team of limiting beliefs and preconceived notions. Workshops also permit the team as a group to identify and rank the principal stakes of its future in various contexts. At the end of this intensive work, participants are in a good position to draw up the organization's priorities, objectives, as well as decide which tools from the strategic foresight toolbox should be used according to a schedule of implementation. The choice of methods (tools) should not be imposed on the team. Nevertheless, these tools are indispensable for the effectiveness of the meetings. Without method there is no common language of exchange, no coherence, and no structured ideas. On the other hand, a method is not an end it itself and one should not be a slave to process. The animator or facilitator must strike a balance.

Before diving headlong into a foresight process, one should pause and consider the nature of the problems posed, the manner about which one intends to inquire, and finally the way in which one intends to apply the solutions. It is useless to waste time treating false problems. We believe that a problem well posed, is already half solved. During the preliminary stages of this process, before engaging dozens of people for several long months, it is useful to simulate the entire process, keeping in mind the inevitable setbacks and intermediate failures. The choice of methodologies used is not only subordinate to the nature of the problem(s) identified, but is also constrained by the time and means allocated for the study. The methods simply provide a way to structure the process for the best possible results. A formal process is also a crucial factor for the cohesion of the group and its motivation, which will ultimately produce the intermediate report. Finally, the choice of method(s) must be made according to the problems confronted, the allotted time, and the accessibility of the method. The method must be sufficiently simple to remain accessible to those who would use them, as well as to the uninitiated to whom the results are often aimed.

\section{Contingent and modular applications}

It is rare to see a foresight exercise undertaken which uses all the tools available in the scenario-building toolbox. Time constraints are simply incompatible with the inherent delays in this type of undertaking. Each of the tools in the strategic foresight toolbox may be used individually. In this way, the facilitation and client teams agree upon the most appropriate tools, and then apply them in a modular way. In some cases, they modify them to fit their needs. The following examples demonstrate the modular nature of the toolbox.

\footnotetext{
${ }^{4}$ See the article by Stephen M. Maurer (2001) [5] dedicated to Fritz Zwicky, the 'father' of morphological analysis, available on the LIPSOR website under the archives tab (www.laprospective.fr).

${ }^{5}$ In certain cases, a seminar of this type could include up to a 100, perhaps even 200 people, working together at the workshops. The implication of a large number of stakeholders is ideal for a regional foresight study.
} 
On the corporate side, it is best to distinguish those scenario planning studies which are highly confidential and used exclusively by executive managers (e.g., Lafarge, Pechiney, Mercedes, or Nestlé) and those which are used as a tool for group process in order to mobilize the collective intelligence of an organization faced with a rapidly evolving external environment (Renault, French Regional Transport, French Ministry of Infrastructure, etc.). These latter studies are highly focused on the communication of strategy as a central objective; whereas with the former, foresight is specifically used for developing enterprise strategy.

To illustrate the former, there is the example of Lafarge. Lafarge represents one of the best case studies where a foresight process has had major consequences on the strategy of an organization. As early as the middle of the 1970s Lafarge had anticipated the decline of the cement industry (approximately $1 \%$ decline per annum beginning at the end of the 20th century). Lafarge decided to make an investment in a promising sector - biotechnologies - and acquired the group Coppée, whose only single common element with the cement was the fact that both industries typically employ little labor. Since that time, Lafarge has been focused largely on materials. Companies like Lafarge are always one step ahead of the curve and have already anticipated the consequences of new construction in Eastern Europe.

In the latter case, foresight is used as a tool for mobilizing employees and communicating strategy throughout the organization. This is a process which involves stakeholders across a wide spectrum of the organization and allows the organization to confront possible changes in their operating environment before they happen. It is quite likely that the restructuring that took place at Renault during the 1980s (cutting the workforce by a third between the years 1985 and 1989) had been facilitated by the foresight workshops they had done during the years 1982 and 1984 under the name MIDES, shorthand for industrial and socio-economic changes. Several thousand executives, managers, and experts had participated in this exercise. In these cases, transparency is critical, and publications concerning the MIDES Project were distributed throughout the organization. In addition, there were several publications circulated throughout Renault concerning the government's projections for the auto industry. These publications serve as a sounding board for the introduction and circulation of ideas.

Between these two extreme types of applied foresight, there is one common theme and several intermediate applications which exist on the continuum and between the poles. The common theme is the cyclical nature of foresight which tends to be marked by highlights every five to seven years. In the long-term, the foundation of the study must be of sufficient quality to last several years.

With regard to the intermediate cases of foresight which are both a tool for strategy and a means to motivate managers, we should cite large petrochemical companies like Shell which have used scenarios for more than 20 years and even go as far as claiming this practice as one of the key elements of their strategy [6]. With respect to the Shell experience, we have remarked simply that the method they use is less formal than the one used in foresight. Scenarios in these contexts have been used to bring together geographically separate and decentralized business entities in order to create a common strategy for the organization. The success of the scenario-planning method had been largely facilitated by oil shocks which had been anticipated as early as 1971-1972.

\section{A double-edged tool}

One aspect of foresight is the systematic use and abuse of scenarios. We do not forget that foresight and scenario are not synonyms. Granted, drafting desirable scenarios as a group may serve a therapeutic purpose; however, the resulting scenarios then become less important than the collective effort. Once a group has decided to consider the future together, it might as well ask the right question(s). Furthermore, the group might as well begin with those questions for which there is little consensus. Why? Tackling contentious issues tends to shake up the established order and force participants to break out of their usual patterns of thinking. Note that scenarios should not be confused with strategic options either because participants in scenario building workshops are not necessarily those on the front lines. The anticipation phase should be collective and should involve the greatest number of people possible. Indeed, this phase employs tools to organize and structure the collective thinking process according to what is at stake in the future as well as the eventual evaluation of strategic options. On the other hand, for reasons of confidentiality or liability, the phase of strategic choices should involve a limited number of participants, e.g., the elected representatives only or a company's board of directors. This final phase requires less scientific methodology and decisions should be made after roundtable discussions and consensus gathering among the leading participants or those in charge. The tools employed here may be useful in choosing strategic options, but the emphasis remains on freedom of choice.

People need the future; in other words, they need hope. This collective need is best expressed if channeled through some form of method. Surprisingly, this corresponds to what psychiatrist Jean Sutter meant when he observed that people's principal and almost sole occupation was to live their future in advance [7]. Let us give two quick reminders here: action without a goal is meaningless and foresight leads to action. In our experience, the complexity of the problems and the need to address them collectively require methods that are as rigorous and participatory as possible so that the individuals involved may identify the appropriate problems and agree upon solutions.

\section{References}

[1] Datar, Travaux et Recherches de Prospective Paris, La méthode des scénarios, La Documentation française, 1975

[2] H. Kahn, Anthony J. Wiener, The Year 2000: A Framework for Speculation on the Next Thirty-Three Years, Macmillan, New York, 1967; Trad, L'an 2000, R. Laffont, Paris, 1968. 
[3] M.E. Porter, Competitive Advantage: Creating and Sustaining Superior Performance, Free Press, New York, 1998.

[4] J. Lesourne, D. Malkin, L'exercice Interfuturs: réflexion méthodologique, Futuribles 27 (October 1979).

[5] S.M. Maurer, Idea man, Beam Line, New York, 2001.

[6] P. Wack, Scenarios: Uncharted waters ahead, Harvard Business Review, 1985;

Scenarios: Shooting the rapids, Harvard Business Review, 1985.

[7] J. Sutter, L'anticipation, Psychiatrie ouverte Paris, Presses Universitaires Françaises, Coll, 1983.

Philippe Durance holds a doctorate in management science. He is an associate professor at the Conservatoire des Arts et Métiers (CNAM) and researcher at the LIPSOR in Paris. He also directs the Prospective collection at the publishing house L'Harmattan (Paris).

Michel Godet holds the chair of Strategic Prospective at the Conservatoire National des Arts et Metiers in Paris ${ }^{6}$. He is also a member of the Council of Economic Analysis attached to the French Prime Minister's office, and the author of several widely translated books. Michel Godet has worked with some fifty companies to make freely available on the internet (www.laprospective.fr) the methods he has developed for rigorous scenario building as an approach that enables us to imagine possible futures and how they can be influenced and managed. He argues that without a project for our own future, scenario building is just entertainment. Godet's last book in English, Creating Futures, Scenario Building as a Strategic Management Tool (Economica 2006) was prefaced by Joe Coates. ${ }^{7}$

${ }^{6}$ Created during the French Revolution to provide higher and continuing education to professionals through evening courses. Jean Baptiste Say was the first holder of a chair of Economics at the Conservatoire, which served as a model for the establishment of the Massachusetts Institute of Technology (MIT) several decades later.

${ }^{7}$ Now available online at http://www.cnam.fr/lipsor/eng/data/creatingfutures2006.pdf. 